the baseline $-14,7 \pm 10,2$ years. All patients retrospectively calculated the 10 -year probability of fractures and prognostic model developed by the IR.

Results: According to the Fracture Risk Assessment Tool, 32 (46\%) patients had a low risk of osteoporotic fractures, $38(54 \%)$ had a high risk. According to the predictive model of IR $33(47 \%)$ patients had a low risk of osteoporotic fractures, $37(53 \%)$ had a high risk. During the follow-up period, osteoporotic fractures were occurred in $18(26 \%)$ patients: $14(78 \%)$ of them had a high risk of fractures according to the predictive IR model, and $13(72 \%)$ patients - according to the Fracture Risk Assessment Tool. Positive and negative predictive value of the Fracture Risk Assessment Tool was 34\% and $84 \%$, respectively, of the predictive model of IR - $38 \%$ and $88 \%$, respectively. Prognosis of the predictive model of IR in $73 \%$ cases coincided with assessing the 10 -year probability of fracture. Conclusion: The predictive model developed at V.A. Nasonova Reasearch Institute of Rheumatology (Russia) showed a higher sensitivity and specificity in determining the risk of osteoporotic fractures in RA patients vs FRAX algorithm. Disclosure of Interests: None declared.

DOI: 10.1136/annrheumdis-2021-eular.1717

\section{POS1109 MULTIVARIATE ANALYSIS OF RISK FACTORS FOR REDUCED BONE MINERAL DENSITY ASSESSED WITH RADIOFREQUENCY ECHOGRAPHIC MULTI SPECTROMETRY (REMS)}

Z. Batalov ${ }^{1}$, M. Nikolov ${ }^{2}$, N. Nikolov ${ }^{2} .{ }^{1}$ Medical University of Plovdiv, University Hospital Kaspela, Plovdiv, Bulgaria; ${ }^{2}$ UMBAL Dr. Georgi Stranski, Rheumatology, Pleven, Bulgaria

Background: Radiofrequency echographic multi spectrometry (REMS) is an innovative radiation-free approach for the assessment of bone mineral density (BMD) at axial sites. The principle of this technology is based on the analysis of native raw unfiltered ultrasound signals, the so called radiofrequency ultrasound signals, acquired during an echographic scan of the lumbar spine and/or femoral neck. [1]. A previous published study showed a high degree of correlation between the T-score values provided by the two techniques-REMS and dual energy X-ray absorptiometry for both lumbar spine and femoral neck [2]. REMS software outputs information about BMD (g/cm2), T-scores, Z-scores [standard deviations (SD)], percentage of body fat and basal metabolic rate [BMR (kcal/ daily)] [3].

Objectives: The aim of the current study is to investigate the multivariate significant risk factors for reduced BMD through REMS technology.

Methods: In this study, a total of 273 women with mean age 62 years (yrs.) \pm 12 yrs. (range 25-88 yrs.) underwent REMS assessments. Subjects were divided into two groups after acquiring information about the spinal T-scores: 1st group with T-scores $\geq-1$ SD and 2nd group with T-scores <-1 SD. Age, weight, height, body mass index (BMI), basal metabolic rate (BMR), body fat and menopausal status were the risk factors included in the multivariate statistical analyses. Binary logistic regression was used to assess which are the significant risk factors for T-score <-1 SD. Youden's indices were calculated for selecting the cut-off points for each risk factor.

Results: 273 women had mean weight of $70.5 \mathrm{~kg} . \pm 15.7 \mathrm{~kg}$. (range $39.4-127 \mathrm{~kg}$.), mean height $157.1 \mathrm{~cm} . \pm 8.8 \mathrm{~cm}$. (range $100-182 \mathrm{~cm}$.) and mean body mass index (BMI) $28.6 \mathrm{~kg} / \mathrm{cm} 2 \pm 6.1 \mathrm{~kg} / \mathrm{cm} 2$ (range $14.9-47.5 \mathrm{~kg} / \mathrm{cm} 2$ ). The mean body fat of the subjects was $37.8 \% \pm 8.8 \%$ (range $9-52 \%$ ) and the mean BMR was 1274.01 $\mathrm{kcal} /$ daily $\pm 163.17 \mathrm{kcal} /$ daily (range 929.7-1908.4 kcal/daily). 260 women $(95.2 \%)$ were attributed to postmenopausal. Age $(p=0.000)$, BMI $(p=0.015)$, menopause $(p=0.006)$ and BMR $(p=0.000)$ were the multivariate significant risk factors for T-score $<-1$ SD. Odds ratio for the risk factor age was 1.16, so each added year of the women's age increased the risk for T-score $<-1$ SD by $1.16 \%$. Women over the age of $65 \mathrm{yrs}$. showed the highest risk for spinal T-score $<-1 \mathrm{SD}$. The odds ratio of the menopause as a risk factor for spinal T-score $<-1$ SD was 9.54 , so postmenopausal women showed about 9.5 times higher risk of T-score <-1 $\mathrm{SD}$ of the lumbar spine than women who still have their period. The increase of $\mathrm{BMI}$ by one $\mathrm{kg} / \mathrm{cm} 2$ decreased the probability of spinal T-score $<-1$ SD by $0.15 \%$ and the increase of BMR by one $\mathrm{kcal} /$ daily decreased this probability by $0.02 \%$. Women with BMI above $28.63 \mathrm{~kg} / \mathrm{cm} 2$ and those with $\mathrm{BMR}>1331.75 \mathrm{kcal} /$ daily were unlikely to develop spinal T-score $<-1 \mathrm{SD}$.

Conclusion: In the current study, multivariate regression analysis was used to develop a specific REMS-based risk prediction model for spinal BMD, corresponding to T-score <-1 SD. Postmenopausal women over age of 65 yrs. with BMI lower than $28.63 \mathrm{~kg} / \mathrm{cm} 2$ and BMR $<1331.75 \mathrm{kcal} /$ daily were at the highest risk for T-score <-1 SD of the lumbar spine.

REFERENCES:

[1] Pisani P, Renna MD, Conversano F, Casciaro E, Muratore M, et al. (2013) Screening and early diagnosis of osteoporosis through X-ray and ultrasound-based techniques. World J Radiol 5(11): 398-410.

[2] Kirilov N. Analysis of dual-energy x-ray absorptiometry images using computer vision methods. (2020) Trakia Journal of Sciences, Vol. 18, Suppl. 1, pp 114-117.
[3] Kirilova E, Kirilov N, Popov I, Vladeva S. (2019) Bone mineral density of lumbar spine and femoral neck assessed by novel echographic approach-Radiofrequency Echographic Multi Spectrometry (REMS). Clin. Cases Miner. Bone Metab., 16 (1), pp. 14-17.

Disclosure of Interests: None declared.

DOI: 10.1136/annrheumdis-2021-eular.1768

\section{POS1110 RELIABILITY OF VERTEBRAL FRACTURE ASSESSMENT ON DUAL-ENERGY X-RAY ABSORPTIOMETRY}

M. Yasmine ${ }^{1}$, S. Mariem ${ }^{1}$, S. Miladi ${ }^{1}$, A. Fazaa ${ }^{1}$, E. Fguiri ${ }^{1}$, L. Souebni ${ }^{1}$, K. Ouenniche ${ }^{1}$, S. Kassab ${ }^{1}$, S. Chekili ${ }^{1}$, K. Ben Abdelghani ${ }^{1}$, A. Laatar ${ }^{1}$. ${ }^{1}$ Mongi Slim Hospital, Rheumatology, Tunis, Tunisia

Background: Vertebral Fracture Assessment (VFA) is a new feature available on modern densitometers. Yet, the assessment of vertebral fracture (VF) status has not become standard practice.

Objectives: Our study aimed to evaluate the reliability of VFA as assessed by a rheumatologist and a radiology technician.

Methods: We conducted a cross-sectional study assessing the performance of low-radiation single energy x-ray absorptiometry VFA for the detection of VF. We selected patients who were assessed for osteoporosis according to screening protocols. Bone mineral densitometry was measured using standard methods over the lumbar spine L1-L4, the total proximal femur, and results were expressed as T-scores. All VFA were independently evaluated by 2 experienced readers: a rheumatologist and a radiology technician for the identification of VF (T4-L4). VF was classified according to the Genant grading system: grade 1 for an anterior, mid or posterior reduction of 20-25\% in vertebral height; grade 2 for a reduction of 25-40\% and grade 3 for a reduction of more than $40 \%$ in vertebral height. A score for the inter-rater reliability between the readers was expressed using the kappa statistic. Results: One hundred patients were included with a mean age of $66.9 \pm 9.5$ years [46.7-83] years. There was a female predominance $(91 \%)$. Nearly half of patients had osteopenia (48.9\%), $27.7 \%$ had osteoporosis and $23.4 \%$ had a normal bone mineral density. On VFA scans, the non-visible vertebra was mostly located in the upper thoracic spine (60\%). The mean number of VF was $1.2[0-3]$ for both readers. According to the doctor's evaluation, $25 \%$ of patients had at least one VF, of which $75.9 \%$ had a Genant grade 1, $17.2 \%$ had a Genant 2, and $6.9 \%$ had a VF grade 3. According to the technician evaluation, at least one VF was found in $36 \%$ of patients. A grade 1 was assessed in $91.7 \%$ of cases, a grade 2 in $8.3 \%$ of patients but no VF grade 3 was assessed. A kappa score for the inter-rater reliability between the readers for VFA was $0.545(p=0.000)$. The overall agreement by grade between the readers was $0.785(p=0,000)$. The exclusion of non-visible vertebra resulted in a better agreement $(k=0.853)$. Further analysis excluding vertebra T4 to D10, revealed a very good agreement $(\mathrm{k}=0.9)$.

Conclusion: Our study showed a low agreement between the readers on VFA and a better agreement when non-visible vertebrae were excluded. Thus, caution should be advocated when relying exclusively on this device.

Disclosure of Interests: None declared.

DOI: 10.1136/annrheumdis-2021-eular.1866

\section{POS1111 DIAGNOSIS OF OSTEOPOROSIS USING RADIOFREQUENCY ECHOGRAPHIC MULT SPECTROMETRY (REMS) AT THE LUMBAR SPINE IN PATIENTS WITH DIFFERENT BODY MASS INDEX}

B. Cortet ${ }^{1}$, E. Dennison ${ }^{2}$, A. Diez-Perez ${ }^{3}$, M. Locquet ${ }^{4}$, M. Muratore ${ }^{5}$, D. Ovejero Crespo $^{3}$, X. Nogués ${ }^{3}$, M. L. Brandi ${ }^{6,7} .{ }^{1}$ University-Hospital of Lille, Department of Rheumatology and EA 4490, Lille, France; ${ }^{2}$ Southampton General Hospital, University of Southampton, MRC Lifecourse Epidemiology Unit, Southapmton, United Kingdom; ${ }^{3}$ IMIM (Hospital del Mar Medical Research Institute), Centro de Investigación Biomédica en Red en Fragilidad y Envejecimiento Saludable (CIBERFES), ISCIII, Musculoskeletal Research Group, Barcelona, Spain; ${ }^{4}$ University of Liège, Department of Public Health, Epidemiology and Health Economics, Liège, Belgium; ${ }^{5}$ Vito Fazzi Hospital, ASL-LE, O.U. of Rheumatology, Lecce, Italy; ${ }^{6}$ FIRMO Foundation, Florence, Italy; ${ }^{7}$ The National Observatory on Fragility Fractures, Florence, Italy

Background: In recent years, the technology based on the analysis of raw ultrasound signals, Radiofrequency Echographic Multi Spectrometry (REMS), has been validated against Dual-energy X-ray Absorptiometry (DXA) for the diagnosis of osteoporosis and risk fracture prediction.

Objectives: The aim of this multicenter observational study was to evaluate the diagnostic performance of REMS with respect to DXA in patients with different body mass index (BMI) categories.

Methods: The inclusion criteria were: Caucasian women; age between 30 and 90 years; referral by their clinician for spinal DXA assessment; absence of significant walking impairment; signed informed consent. 
Patients underwent DXA and REMS scans at the lumbar spine, according to the procedures described in Di Paola et al. [1], including an a-posteriori quality check of the examinations in order to guarantee the maximum reliability of the diagnostic outputs.

Three groups of patients were considered according to $\mathrm{BMI}:$ : underweight $\left(B M l<18.5 \mathrm{~kg} / \mathrm{m}^{2}\right)$, normal weight $\left(\mathrm{BMl} \geq 18.5 \mathrm{~kg} / \mathrm{m}^{2}\right.$ and $\left.<25 \mathrm{~kg} / \mathrm{m}^{2}\right)$, and overweight/obese $\left(B M I \geq 25 \mathrm{~kg} / \mathrm{m}^{2}\right)$. DXA and REMS BMD values were also stratified in 3 diagnostic categories: osteoporotic, osteopenic, or healthy.

The degree of correlation between DXA and REMS BMD values was quantified by calculating Pearson's correlation coefficient $(r)$. The diagnostic concordance between REMS and DXA was assessed by Cohen's $K$ considering the 3 diagnostic categories. REMS's sensitivity, specificity, positive predictive value (PPV) and negative predictive value (NPV) for discriminating patients with and without osteoporosis were also calculated using DXA outcomes as reference. The same statistics were calculated accepting a $0.3 \mathrm{~T}$-score tolerance on T-score values of borderline cases [1]

Results: Overall, 4282 patients were enrolled and, after the quality check, 3501 couples of scans were included in the analyses. Of these patients, $122(3.5 \%)$ were underweight, 1964 (56.1\%) were normal weight, and 1415 (40.4\%) were overweight. The results of the diagnostic performance in patients after BMI stratification are reported in Table 1.

Conclusion: We observed an excellent correlation between REMS-based diagnosis with respect to the osteoporosis diagnosis performed by DXA in patients from each BMI category. These results indicate that lumbar spine REMS analysis is a suitable and accurate diagnostic tool for patients with different BMI. REFERENCES:

[1] Di Paola M et al. Osteoporos Int. 2019 Feb;30(2):391-402.

Table 1. Diagnostic performance of REMS with respect to DXA considered as reference for patients of different body size.

\begin{tabular}{lccccccccccc}
\hline $\begin{array}{l}\text { BMI } \\
\text { categories }\end{array}$ & $r$ & \multicolumn{4}{c}{ No tolerance } & \multicolumn{4}{c}{ 0.3 T-score tolerance } \\
\cline { 2 - 10 } & & Sens. & Spec. & PPV & NPV & $K$ & Sens. Spec. PPV & NPV & $K$ \\
\hline Underweight & 0.946 & 97.5 & 91.5 & 86.8 & 98.4 & 0.89 & 98.2 & 93.2 & 89.2 & 99.3 & 0.91 \\
Normal weight & 0.946 & 92.6 & 94.4 & 87.0 & 96.9 & 0.85 & 97.5 & 96.7 & 92.3 & 99.0 & 0.93 \\
Overweight & 0.930 & 86.7 & 95.8 & 84.8 & 96.4 & 0.82 & 96.3 & 97.8 & 92.1 & 99.0 & 0.93
\end{tabular}

Abbreviations: $\mathbf{B M I}=$ body mass index; $\boldsymbol{r}=$ Pearson correlation coefficient; Sens. $=$ sensitivity Spec. = specificity; $\mathbf{P P V}=$ positive predictive value; $\mathbf{N P V}=$ negative predictive value; $\boldsymbol{K}$ Cohen's K.The authors BC, ED, ADP, ML, MM, XN, DOC are equal contributors listed in alphabetical order.

Disclosure of Interests: None declared

DOI: 10.1136/annrheumdis-2021-eular.2337

\section{POS1112 COMPARISON OF TWO APPROACHES IN FRACTURES RISK ASSESSMENT IN WOMEN WITH RHEUMATOID ARTHRITIS AND GLUCOCORTICOID USE}

N. Grygorieva ${ }^{1}$, V. Povoroznyuk ${ }^{1}{ }^{1}$ State Institution "D. F. Chebotarev Institute of Gerontology NAMS of Ukraine", Department of Clinical Physiology and Pathology of Locomotor Apparatus, Kyiv, Ukraine

Background: Nowadays, FRAX is the most useful tool for osteoporotic fracture risk assessment that is included in many guidelines. Rheumatoid arthritis (RA) and glucocorticoid (CG) use are two crucial factors for osteoporotic fractures included in FRAX algorithm. According to the last ACR guidelines for the treatment of GC-induced osteoporosis [1], it was recommended to divide the patients into three groups of fracture risk (high, medium and low) that have a great impact on treatment decision. Recently, we received own Ukrainian thresholds [2] for the national version of FRAX that are age-dependent and now widely used in clinical practice.

Objectives: Our study was aimed to compare two approaches (ACR-2017 and Ukrainian (2019) recommendations) in fracture risk assessment in women with RA and GC use.

Methods: We examined 195 females with RA aged 40-89 years old who took GC (at dose $\geq 5 \mathrm{mg} / \mathrm{d}$ for $\geq 3$ months) due to RA. The 10 -year probabilities of major osteoporotic (MOFs) and hip fractures (HFs) were calculated with and without bone mineral density (BMD) using the Ukrainian FRAX model [3]. The DXA was used to measure the lumbar spine, femoral neck and total body BMDs; $T$ and $Z$ scores were calculated (DISCOVERY Wi, Hologic, Inc., USA).

Results: FRAX indexes for MOFs and HFs without BMD in patients with RA and GC were (Me [25-75Q]) 12.0 [8.1-18.0] and 4.2 [1.7-7.2] \%. The correspondent FRAX indexes with BMD were 13.5 [8.5-20.0] and $5.1[1.8-8.7] \%$.

$50 \%$ of examined women had previous fractures and $20 \%$ had previous vertebral fractures. BMD of the femoral neck consisted of $0.62 \pm 0.13$ and L1-L4 BMD was $0.85 \pm 0.15 \mathrm{~g} / \mathrm{cm}^{2} .89 \%$ of females had low BMD at the lumbar spine and / or femoral neck ( $49 \%$ osteoporosis and $40 \%$ osteopenia).
$61 \%$ of women required antiosteoporotic treatment according to ACR-2017 guideline (17.4\% of them a had high risk of MOF and $43.1 \%$ moderate one) without BMD measurement and $64 \%$ of subjects after DXA scan.

According to Ukrainian national guideline, $57 \%$ of patients required antiosteoporotic treatment without BMD measurement and $42 \%$ - after additional DXA examination. After BMD measurement in subjects who required the DXA scan, $78.2 \%$ of females with RA and GC use required antiosteoporotic treatment (additionally to calcium and vitamin D, lifestyle modifications).

Conclusion: Approximately $60 \%$ of subjects with RA and GC use required antiosteoporotic treatment without additional DXA measurement according to correspondent FRAX indexes from both guidelines. The proportion of women requiring treatment after DXA scan is slightly higher according to Ukrainian recommendations. It proves that both of them can be used effectively in daily clinical practice for fracture risk assessment in females with RA.

\section{REFERENCES:}

[1] Buckley L, Guyatt G, Fink HA, Cannon M et al. 2017 American College of Rheumatology Guideline for the prevention and treatment of glucocorticoid-induced osteoporosis. Arthritis \& Rheumatology, 2017;69(8), 15211537. DOI:10.1002/art.40137

[2] Povoroznyuk V, Grygorieva N, Kanis JA et al. Ukrainian FRAX: criteria for diagnostics and treatment of osteoporosis. Pain. Joint. Spine. 2019;9(4):7-16 DOI: 10.22141/2224-1507.9.4.2019.191921

[3] Povoroznyuk VV, Grygorieva NV, Kanis JA et al. Epidemiology of hip fracture and the development of FRAX in Ukraine. Arch Osteoporos. 2017;12(1):53. DOI: 10.1007/s11657-017-0343-2.

Disclosure of Interests: Nataliia Grygorieva Consultant of: Servier, Redis, Vladyslav Povoroznyuk: None declared.

DOI: 10.1136/annrheumdis-2021-eular.2448

\section{POS1113}

ANTIRESORPTIVE THERAPY AFTER TERIPARATIDE DISCONTINUATION - WHEN IS THE BEST TIME TO STARTING IT?

M. Rato $^{1}$, F. Oliveira Pinheiro ${ }^{1}$, S. Garcia ${ }^{1}$, B. M. Fernandes ${ }^{1}$, D. Fonseca ${ }^{2}$, D. Santos Oliveira ${ }^{1,3}$, A. Martins $^{1}$, F. R. Martins ${ }^{4}$, A. Bernardo ${ }^{1}$, R. Ferreira ${ }^{1}$, M. Bernardes ${ }^{1,5}$, L. Costa ${ }^{1} .{ }^{1}$ Centro Hospitalar Universitário de São João, Rheumatology, Porto, Portugal; ${ }^{2}$ Centro Hospitalar Vila Nova de Gaia/Espinho, Rheumatology, Vila Nova de Gaia, Portugal; ${ }^{3}$ Faculdade de Medicina da Universidade do Porto - FMUP, Center for Health Technology and Services Research (CINTESIS), Porto, Portugal; ${ }^{4}$ Centro Hospitalar Universitário do Algarve - Faro, Rheumatology, Faro, Portugal; ${ }^{5}$ Faculdade de Medicina da Universidade do Porto - FMUP, Rheumatology, Porto, Portugal

Background: Treatment with teriparatide (TPTD) is associated with reduction of fracture risk in patients with severe osteoporosis. This drug can only be used for up to 2 years. After that a treatment course with antiresorptives should be considered, in order to prevent the rebound of bone turnover observed after TPTD discontinuation. In this regard, interest in sequential osteoporosis therapy has grown in recent years but the ideal timing for starting another treatment after TPTD is not well established.

Objectives: The aim of this study is to assess if the timing of onset of antiresorptive therapy after TPTD discontinuation has implications in total hip bone mineral density (BMD) and in fracture risk.

Methods: We performed a retrospective cohort study that included patients with severe osteoporosis treated with TPTD $20 \mathrm{mcg} / \mathrm{day}$ for 24 months and followed for at least 2 more years in the rheumatology department of a tertiary university hospital. For analysis, demographic and clinical data and results of dual-energy X-ray absorptiometry (DXA) after cessation of teriparatide were used. For comparison between groups Mann-Whitney $U$ test was used.

Results: Fifty-five patients with osteoporosis, with a median age of 68 (32-85) years, were included. Forty-nine patients were female (89.1\%). Nineteen patients $(34.5 \%)$ had primary osteoporosis and 36 (65.5\%) glucocorticoid-induced osteoporosis. The median time for initiating antiresorptive treatment was $7(0-35)$ months after cessation of TPTD. Forty-three patients $(78.2 \%)$ started a bis phosphonate, 6 denosumab $(10.9 \%)$ and 6 patients did not receive any other treatment. The most prescribed bisphosphonate was zoledronate (69.8\%). All patients received calcium and vitamin D supplementation. After completion of TPTD regimen 8 patients experienced at least one fragility fracture (14.5\%). At follow-up, $37(67.3 \%)$ of patients underwent DXA on average $30.0 \pm 15.4$ months after starting antiresorptive agents. The median total hip BMD in patients who started antiresorptive therapy in the first 12 months (inclusive) after cessation of TPTD regime was $0,738(0.587-0.993) \mathrm{g} / \mathrm{cm}^{2}$ and the median total hip BMD of patients who started therapy after one year of discontinuation of TPTD was $0.683(0.390-0.813) \mathrm{g} / \mathrm{cm}^{2}$. This difference is marginally significant $(\mathrm{p}=0.067)$ The median time in starting antiresorptive treatment is higher in patients with new fragility fractures after TPTD than in patients without new fractures however this difference was not statistically significant (10.0 [2-35] vs $6.0[0-35]$ months; $\mathrm{p}=0.393$, respectively). 